\title{
Public Healthcare in Canada: does it work?
}

Paul T E Cusack

23 Park Ave. Saint John, NB E2J 1R2, Canada

*Corresponding author: Paul T E Cusack, 23 Park Ave. Saint John, NB E2J 1R2, Canada

Received date: June 18, 2020; Accepted date: July 20, 2020; published date: July 24, 2020

Citation: Paul T E Cusack. Public Healthcare in Canada: does it work? J Clinical Research and Reports, 5(1); DOI:10.31579/2690-1919/099

Copyright: (C) 2020 Paul T E Cusack. This is an open access article distributed under the Creative Commons Attribution License, which permits unrestricted use, distribution, and reproduction in any medium, provided the original work is properly cited.

One of the great things about living in Canada, is that all citizen, regardless of their ability to pay, receive government paid health care. However, access to healthcare is not distributed equally across the land. There is better service in urban areas than rural, and better in larger urban than smaller urban areas.

A lot of newly minted doctors don't want to set up practice in poorer areas of the country. Although the provinces have tried to ameliorate this problem, I'm not sure at how effective its has been. The idea of a billing number for a medic set to a local may infringe on the rights of doctors, although in general, employers can offer a job at a certain address. In New Brunswick, probably one of the poorest provinces in the country, has set up a medical school after all these centuries, in conjunction with the world-famous Dalhousie University (DalMed) in an attempt to encourage medical students to stay here where they are educated in medical science. They don't always stay- in fact - thee flee after the graduate with a free medical education to the US.

Another ploy was to allow Nurse Practitioners to deal with run of the mill maladies. I'm not sure what kind of liability a nurse would have if he/she didn't pick up on something serious that leads to a worsening condition for the patient. Allowing foreign doctors to set up in Canada seems to work well. Some countries in the Caribbean for example, has a surplus of doctors. What the medical certification requires $\mathrm{s}$ is unknown to me, but of courses there is always the testing with examinations that, although difficult, may be too strenuous to encourage doctors to practice in Canada.

There are also after-hours clinics usually associated with a pharmacy. The way they work is that someone must call for the patient and register a visit for that day of evening. Its not the way I think organized healthcare should work. If you can't see a doctor when you desperately need on, is that a system that works?

Some nurses work as social workers in the community. There is a great shortage of such workers and the needs of the population go unsatisfied.

I recently contracted covid-19 I think. I had all the symptoms. It would have taken four day to get int o see a doctor. By the time I got in, I was told not to worry about it. I suppose I'd have had to go to the Emergency Room at the local hospital and wait with other sick people in a crowed room for 10 to 12 hours. This is the reality for many New Brunswickers who simply don't have a family doctor. They must rely on the emergency room.

Canada is a great country. Free Health care is a boon, when it works. I wonder what it would be like not to be able to have health insurance in the United States for example. Of course, the world over, there is no access to health care whatsoever. We also don't include dentistry in our "free" health care system. If your teeth and gums are not healthcare, what are they? Still I'd take the Canadian system over others.

There is a danger of having too much money in healthcare. Doctors who are in it for the money I suggest, don't make the best professionals. And is there really a fair balance between what a dock earns versus a pharmacist for example. I'm told hat the increase in the renumeration for a nurse practitioner doesn't offset the added liability by one nurse.

I wonder if it can be improved upon such as a private system for those who can afford it and lessen the burden on the government system. Of course, if we have a two-tier system, the government is creating of strata in the citizenship of Canadians. No wonder healthcare is the number one issue in American politics these days. 